Article

\title{
Policy Assemblages and Policy Resilience: Lessons for Non-Design from Evolutionary Governance Theory
}

\author{
Kris Hartley ${ }^{1}$ and Michael Howlett ${ }^{2, *}$ \\ ${ }^{1}$ Department of Asian and Policy Studies, Education University of Hong Kong, Hong Kong S.A.R.; E-Mail: hartley@eduhk.hk \\ 2 Department of Political Science, Simon Fraser University, Canada; E-Mail: howlett@sfu.ca \\ * Corresponding author
}

Submitted: 10 February 2021 | Accepted: 1 April 2021 | Published: 25 June 2021

\begin{abstract}
Evolutionary governance theory (EGT) provides a basis for holistically analyzing the shifting contexts and dynamics of policymaking in settings with functional differentiation and complex subsystems. Policy assemblages, as mixes of policy tools and goals, are an appropriate unit of analysis for EGT because they embody the theory's emphasis on co-evolving elements within policy systems. In rational practice, policymakers design policies within assemblages by establishing objectives, collecting information, comparing options, strategizing implementation, and selecting instruments. However, as EGT implies, this logical progression does not always materialize so tidily-some policies emerge from carefully considered blueprints while others evolve from muddled processes, laissez faire happenstance, or happy accident. Products of the latter often include loosely steered, unmoored, and 'non-designed' path dependencies that confound linear logic and are understudied in the policy literature. There exists the need for a more intricate analytical vocabulary to describe this underexplored 'chaotic' end of the policy design spectrum, as conjuring images of 'muddles' or 'messes' has exhausted its usefulness. This article introduces a novel metaphor for non-design - the bird nest-to bring studies of policy design and non-design into lexical harmony.
\end{abstract}

\section{Keywords}

Evolutionary Governance Theory; policy assemblages; policy design; policy instruments; policy metaphors; policy mixes; policy non-design; public policy

\section{Issue}

This article is part of the issue "Steering in Governance: Evolutionary Perspectives" edited by Kristof Van Assche (University of Alberta, Canada / University of Bonn, Germany) and Raoul Beunen (Open University, The Netherlands).

(C) 2021 by the authors; licensee Cogitatio (Lisbon, Portugal). This article is licensed under a Creative Commons Attribution 4.0 International License (CC BY).

\section{Introduction}

Policy design "involves the purposive attempt by governments to link policy instruments or tools to the goals they would like to realize" (Howlett \& Mukherjee, 2017, p. 140). Dimensions of policy design, including processes and outcomes, have been viewed as existing along a spectrum from ordered (designed) to disordered (nondesigned). While the ordered end of the spectrum is well studied and theorized, there is little useful analytical language to describe the less-ordered end of the spectrum. Metaphors like 'muddles' (Lindblom, 1959), 'messes'
(Roe, 2016), 'garbage cans' (Cohen et al., 1972), and 'anthills' (Czarniavswka, 2009) have either exhausted their value or fail to capture the level of nuance required for a deeper analysis of 'non-design.' More intricate and nuanced analytical vocabulary is needed to resolve the ambiguity plaguing such metaphors, particularly regarding their ability to go beyond rudimentary descriptive issues to capture intangible forces (e.g., habits and institutions) that hold policies together in the absence of structuring intent.

This article takes mixes of policy goals and instruments (hereafter labeled 'policy assemblages') as 
units of analysis in the study of non-design from an Evolutionary Governance Theory (EGT) perspective; this unit of analysis is more analytically meaningful in exploring policy processes and outcomes than are individual policy instruments. Drawing from EGT, the article explores how the emergence, endogenous evolution, and proactive refinement of policy assemblages are the product of a complex mix of factors including policy ideas, political ideologies, and habits of governance ossified over time.

Non-designed policy assemblages are increasingly common amidst growing complexity in the nature of policy problems and efforts to address them. However, studies of policy formulation and design have struggled to systematically engage with the concept of non-design. Indeed, scholars increasingly see policy change as a contested, negotiated, and constructed phenomenon shaped by a diverse mix of actors, ideas, institutions, and contiguous subsystems (Bemelmans-Videc, 1997; Bressers \& Klok, 1988; Capano \& Lippi, 2017; Fischer, 2019; Howlett et al., 2009; Linder \& Peters, 1991; Peters, 2002; Zittoun, 2009). Such factors conceptually introduce instability and disruption into what designbased theories would posit is a rational and logical policy process, thus requiring additional efforts to better theorize and empiricize both design and non-design. As Van Assche et al. (2014, p. 46) argue with respect to EGT, the "continuously shifting discursive environment" of governance invites a deeper incorporation of evolution and related concepts as alternative metaphors for policymaking.

The practical exigencies of policymaking are often constructed and given effect in accordance with an historically dominant instrumental-rationalist epistemic (Hartley \& Kuecker, 2021). Reconciling the embedded legacy of epistemic determinism with the emergent concept and reality of epistemic fluidity or liminality-more art than science-is necessary in an era of increasingly complex problems and contested problem understandings. However, this reconciliation is deeply uncomfortable for policy practice due to the monopolistic influence of formalism on 'serious' analysis and to political demands for policy outcomes that are immediate and measurable only through prevailing epistemics and their methods. These circumstances reward perfunctory and expedient efforts like patching while abhorring the sluggishness and hassle of systemic transformation and associated epistemic reckoning. As the complexity of policy problems and evolving governance structures can undermine the practical and epistemic coherence of policy assemblages, deeper scholarly contemplation of non-designed policymaking processes and outcomes is warranted (Adam et al., 2019).

This article addresses the evolutionary nature of policy non-designs for complex problems by drawing from the natural world a metaphor concerning how elements of policy assemblages cohere amidst complexity, contestation, and even chaos in their creation and opera- tion. The article proceeds by discussing the potential usefulness of a new metaphor for policy non-design-the bird nest-that is inspired by a recent study in applied physics. It continues by specifying the metaphor along four analytical dimensions that explain the durability of non-designed policy assemblages: structural integrity, diversity of constituent elements, capacity to absorb stress, and boundary elements as containment mechanisms. The article concludes with reflections about how the metaphor can support efforts to strengthen the methodological specification of non-design in the policy sciences.

\section{Towards a More Complete Metaphor for Policy 'Non-Design'}

Historically, the process of policy design has been conceived as one in which policymakers obtain evidence and facilitate interactions among stakeholders in the process of arriving at authoritative decisions about the course of government activity ('policy'; Colebatch, 2018). Despite the allure of this elegant conceptualization, rational and technically deterministic processes are often absent from policy processes. The resulting policy assemblages bear this imprint by assuming characteristics of 'non-design' in their adoption and implementation, leading them to appear deficient in conceptual 'elegance' and parsimony (Howlett \& Mukherjee, 2014).

Capano and Howlett (2020) have highlighted the dearth of scholarly attention given to the connection between sectoral politics and ideational paradigms, and to their links with the content and trajectories of policy assemblage choices. Nevertheless, contemporary studies of wicked problems in areas such as climate change show that instances of non-design appear to be more frequent as sectoral boundaries and process routines no longer condition how policymakers and publics think about complex policy problems (Hartley et al., 2019; Head, 2019; Nair \& Howlett, 2017a; Peters \& Tarpey, 2019). These studies suggest that non-designed assemblages can be the product of a variety of a-rational phenomena including malfeasance, accident, and unproductive or incomplete negotiation of conflicting interests. Furthermore, such processes and practices can frustrate the efforts of many policymakers and analysts to conceptually rationalize the function of policies (Head, 2010; Howlett, 2020; Howlett \& Mukherjee, 2014).

From a mechanical perspective, non-designed policy assemblages differ from those of designed assemblages in notable ways. For designed assemblages, policy instruments and the mechanics of connecting them are comparable to the ordered and interlocking structural elements of a building (e.g., where beams, walls, and joints cohere). Further, the political aspects of decisionmaking that facilitate the formal adoption of a particular design can be compared to those that shape the aesthetic preferences of architects, engineers, and city planners (e.g., choices about a building's size, style, materials, 
and associated zoning limitations). Nevertheless, such metaphorically straightforward conceptualizations do not fully capture the less rational and deterministic aspects of policy assemblages. The natural movement towards complexity and disorder in society, a type of entropy assumed by EGT, invites an alternative perspective for holistically understanding the shifting contexts and dynamics of policymaking. Critics of excessive formalism in policy design often argue, in accordance with EGT, that macro-conditions and local contextual idiosyncrasies often impede efforts to hermetically rationalize and analyze policy problems and calibrate solutions, particularly as overlapping and contingent systems co-evolve and policy legacies become entrenched (Van Assche et al., 2017).

An emerging line of research examines the potential for fresh understandings about policy change at the intersection of complexity and evolutionary governance; for example, Bubak's (2021) 'structure-inevolution' approach emphasizes distinct evolutionary and adaptive patterns in particular types of policy systems. EGT argues that these governance and policymaking outcomes emerge amidst the functional differentiation, complex subsystems, and varying temporal dimensions of policymaking contexts that render instances of non-design inevitable (Van Assche et al., 2017). Examples of common processes that lead to such outcomes are cases in which time and knowledge are limited (e.g., Covid-19 pandemic response) and in which conflict among actors in subsystems pervades deliberations and decision-making processes (Weirich, 2004).

From this view, non-designed policy assemblages can lack the logical functionality that in some evolutionary perspectives is often assumed to terminate in evolutionary dead-ends or failures. However, empirical observation shows that non-designed assemblages can endure over considerable lengths of time despite their structural heterodoxy. Many such assemblages are complex and durable systems that emerge from processes in which components are often woven together strategically but also opportunistically or accidentally. These 'naturalistic' systems (resembling phenomena that occur in nature) are reflective of seemingly disordered but functional phenomena such as the anthills that Czarniavswka (2009) uses as a metaphor to describe the development of complex organizations through the entrepreneurial activities of self-interested actors.

A similar metaphor-that of a bird nest-has been used by research in applied physics to describe the structural mechanics of complex component assemblages emerging from interdependent and disorganized building processes. In their study of the functionality of bird nests from the perspective of materials science, Weiner et al. (2020) identify the presence of an instinctive evolutionary or 'natural' logic that draws on the characteristics of materials, their inter-relationships, and the stabilizing role these materials play in a structural system. The authors argue that "real bird nests have inspired scientific study for hundreds of years, but the underlying logic from a practical, physical perspective is coming closer to focus with research into both nest structure and building behavior" (p. 11).

From a policy perspective, both the anthill and bird nest metaphors acknowledge that complex structures can emerge in the absence of a 'blueprint' and can thus be applied to understand the many instances of policymaking and policy design where formal or structured intent is missing. However, the bird nest metaphor adds deeper analytical nuance than do metaphors such as 'anthills' by considering the characteristics of policy assemblage structure (e.g., components used to construct nests) as reflective of the diversity of 'materials' available 'at hand' - that is, instruments, tools, and norms coalesce to form a disordered but effective and durable policy assemblage. The bird nest metaphor and its implicit invocation of 'bricolage' (Levi-Strauss, 1966) lends itself better to the analysis of non-designed processes than do architectural metaphors, because using formal architectural language in non-design settings generates the expectation that a structure improperly engineered or constructed would simply collapse under duress rather than endure indefinitely.

\section{Four Analytical Dimensions of the Bird Nest Metaphor Applicable to Policy (Non)Design}

The bird nest metaphor helps resolve the otherwise paradoxical image of a long-lasting but unstructured edifice (e.g., a non-designed policy assemblage). A bird nest can be seen not simply as shorthand for the chaotic, disordered, and clumsy mélange of disparate elements but as a product of evolutionary wisdom and instinct; such dynamics can also exist among policymaking institutions and actors, whose effectiveness is evident in their survival (if not in their formal design). The practical insight emerging from this metaphor is that evolutionary wisdom and instinct in policymaking - the products of tradition, policy styles, and path dependencies (Howlett \& Tosun, 2018; see also Enkler et al., 2017; Haydu, 2010)fills gaps left by the absence of formal design, intent, and rationality. Accordingly, non-designed assemblages may be seen as structurally resilient despite lacking many of the characteristics demanded by the logics of formal design.

As it is applied here, the bird nest metaphor takes inspiration from Weiner et al.'s (2020) naturalexperimental work in the field of applied physics. That work, as previously mentioned, examines the resilience of structures from the perspective of mechanical integrity, diversity of constituent elements, capacity to absorb stress, and boundary elements as containment mechanisms against which to load a structure's outwardpressing 'force chain.' The latter is illustrated by Weiner et al. (2020) as reflecting the difference between a bird nest and a grain silo: Both are structurally coherent and finite, but only the latter has externally imposed 
containment mechanisms-the walls of the silo-that offset relatively weak cohering friction among the materials (individual grains) being contained. This is a crucial dimension of the metaphor, as policy assemblages often lack such a structuring mechanism but hold together through internal frictions and dependencies. According to Weiner et al. (2020), filaments-sundry items and 'dis-ordered meta-materials' collected by birds for building nests-can, when randomly and tightly packed, enhance structural resilience; the authors label this resilience an "elastoplastic response to oedometric compression" (p. 1).

The bird nest metaphor in the policy realm conceptualizes material packing density and frictions, mechanical response to stress, and internal boundary elements as, respectively, the characteristics of policy instruments within an assemblage, their collective resilience against stress, and their coherence as largely independent of exogenous threats and constraints. The resulting policies are often regarded as weak and inefficient but, like a bird nest, their ad hoc and unstructured nature provides some redundancies that allow them to absorb unanticipated stresses and ultimately to exhibit resilience.

As such, the metaphor has potential usefulness in capturing the chaotic but functional side of a Levi-Straussian continuum referenced by Howlett and Mukherjee (2014): The formal and deterministic techne of policy design being informed by evidence, best practices, and first principles, as against the bricolage of policy non-design seen as ill-informed by knowledge, cobbled together somewhat randomly, and layered non-strategically over time (Johnson, 2012; Levi-Strauss, 1966).

Methodologically, within the policy sciences the defining characteristic of such 'non-designs'-their absence of macro-stylistic cohesion-has eluded the application of common metaphors in the field that rely on assumptions about formal design.

Analyzing the individual components of such a policy or policy assemblage through an EGT perspective invites use of the bird nest metaphor because policy components in isolation-such as a subsidy or a penalty-often have less complexity than the entity they combine to form. The bird nest metaphor captures the processes of randomness, stochasticity, and even chaos common to many natural and social systems and characteristic of much policymaking (Feldman, 2019; Kiel \& Elliott, 1996; Young, 1991). The random packing of components in a nest, for example, bears similarity to the kinds of logrolling and mutual support that legislators and decisionmakers often use in negotiating the particulars of policy initiatives that, once enacted, can remain in place to 'cement a deal' for an extended period (Dyckman, 2018; Lindblom, 1959).

To more clearly illustrate how the metaphor is applied, Table 1 provides a comparison of the metaphor's vehicle (bird nest) and tenor (policy assemblage) across 'components' (as constituent elements comprising the whole), 'resilience' (as the structural capacity and capability of the assemblage), and 'coherence' (as a qualitative characteristic of the assemblage). The remainder of this section elaborates on this content by discussing each of the aforementioned analytical elements and their function within the metaphor: structural integrity and diversity of constituent elements (components), capacity to absorb stress (resilience), and boundary elements (coherence).

\subsection{Dimension 1: Structural Integrity Emerging from Disorder}

Recognizing, if implicitly, the applied lessons of Benyus' (1997) work on 'biomimicry,' Weiner et al. (2020, p. 2) argue that conventional theories about humanly design can learn from natural ones, and that "our [humanly] intelligent, prescriptive design process has proven successful, but could only stand to benefit by emulating strategies of naturally-selected design, which rely on emergent properties of disordered matter."

Applied to public policy, the bird nest metaphor implies that the collective strength of multiple policy instruments generates time-fortified interdependencies and complementarities that can produce an endogenous logical coherence matched to a given setting, even amidst exogenous stress and the failure or alteration of constituent instruments to meet formal standards of coherence and consistency. In the policy realm, cognate processes such as decision accretion, patching, and layering often result from conflicting or inconsistent priorities

Table 1. Summary comparison of bird nest and policy assemblage concepts.

\begin{tabular}{lll}
\hline & Bird nest (Weiner et al., 2020) & Related 'policy assemblage' concepts \\
\hline Components & $\begin{array}{l}\text { Characteristics, loadings, and friction points } \\
\text { of nest packing materials }\end{array}$ & $\begin{array}{l}\text { Characteristics, choices, designs, interactions, } \\
\text { and inventories of policy instruments }\end{array}$ \\
Resilience & $\begin{array}{l}\text { Mechanical response to stress and potential } \\
\text { for 'reproducible behavior' (reversion to } \\
\text { original form) }\end{array}$ & $\begin{array}{l}\text { Durability of policy assemblage amidst uncertainty, } \\
\text { systemic disruption, and incidental exogenous } \\
\text { shocks }\end{array}$
\end{tabular}

Coherence Boundary effects, bricolage, 'jammed' state

Policy coherence, path dependence, policy layering, policy ossification, institutional stasis/inertia 
over time, as policymaking bodies come under the control of a rotating mix of political or ideological regimes seeking to make their own institutional imprint (Howlett \& Rayner, 2013; Weiss, 1980). Under such circumstances, internal redundancies and contradictions in a policy can sometimes enhance its resilience, serving as institutionalized checks-and-balances on the tendency towards over- and under-designing policies that commonly characterizes formal policymaking processes (Maor, 2020). Although such policy assemblages can have occasional micro-dissonance in the form of short-term incoherence or inconsistencies, they may also have longer-term macro-durability, enabling the survival of the assemblage amidst stress.

\subsection{Dimension 2: Diversity of Constituent Elements}

The bird nest metaphor helps to better conceptualize the diverse characteristics of elements constituting policy assemblages. According to Weiner et al. (2020), nest materials can be assessed on their physical characteristics and shape types (e.g., spheres/discs, ellipsoids/ spheroids, high/low aspect ratio cylinders, and flexible/frictional rods) rather than on purely structural functions. The authors argue that "the evolutionary value of the bird nest appears to be in the mechanical properties of its jammed state, specifically those emerging from a subtle interplay between geometry, elasticity, and friction between its slender, flexible elements" (Weiner et al., 2020, p. 2). The collective coherence of these aggregated nest materials is derived in part from the capacity of flexible rods to be packed in ways that maximize density and volume through random 'reorientations' (passive repositioning that declines over time and leads to materials settling into a stable state).

These characteristics are again reflected in similar dynamics found in many non-designed policy assemblages. Unlike in a more formally designed building, for example, these assemblages become more layered and complex as they evolve (as do wines and cheese, to invoke other metaphors deserving additional research). Inconsistencies arise but over time the policy assemblage achieves equilibrium or stasis through its 'jammed state.' This state emerges as instruments are repositioned to adapt to changes not only externally under contextual circumstances (e.g., macro-economic, geopolitical, and environmental) but also internally within a mix of complementary policies (e.g., shifting political preferences for instrument choice, redesign or introduction of new instruments, and resource or funding alterations). Both types of repositioning can lead to a serial progression of momentarily 'settled' states, each of which is a consequence not of strategic visioning but of novel and fleeting circumstantial mandates. This dynamic is reflective of reiterated problem-solving policymaking processes described as 'process sequencing' (Daugbjerg, 2012; Haydu,1998; Howlett, 2009).

\subsection{Dimension 3: Capacity to Endure External Stress}

Bird nests are capable of absorbing substantial external stress, as are policy assemblages. According to Weiner et al. (2020), the repeated compacting (through laboratory-induced mechanical stress) of the aggregate materials of a bird nest leads to the nest's decreasing plasticity over time. The authors describe this plasticity as a 'meta-material property' in which the structural integrity of materials is maintained even as the policy assemblage evolves from a loosely packed state to a 'random close packed limit.' The authors state:

As the aggregate loads and deforms, a given interparticle contact experiences shear. Upon overcoming static friction, the contact slides to a new equilibrium position. The contact returns to its original position(s) as the load is relieved but only after overcoming static friction in the opposite direction. The return trip is less 'springy' because the previous deformation is still temporarily stored in the network of frictional contacts. (Weiner et al., 2020, p. 7)

These descriptions suggest vivid and useful connotations for policy assemblages that accord with recent studies of policy resilience and agility (Capano \& Woo, 2018; Howlett, 2019). Through repeated stress, the accumulated effect of incremental adjustments to the characteristics of a policy assemblage and its constituent elements leads to progressively higher degrees of statutory specification and thus more institutional rigidity (that is, the endurance of existing institutional structures and practices amidst external forces pressuring them to change). Components of the assemblage co-evolve into mutual dependence and stability, even in the absence of ex ante engineering, and static friction becomes the ossifying force that induces policy stasis and equilibrium.

A policy assemblage thus may begin with disparate and random instruments, but these instruments can collectively congeal into a stable entity over time. Through processes such as patching and sequencing of new instruments, the mechanisms and institutions that connect them strengthen, while supportive ideologies and normative goals may become more coherent and gain political strength as internal interests and dependencies among actors solidify (Howlett \& Rayner, 2013). At the same time, transformative stress events can induce permanent changes in constituent instruments or in their relative position within the assemblage-such as the permanent adoption of distance learning platforms after the Covid-19 pandemic (Liu et al., 2020). During such a stress event, instruments may shear relative to one another in a liminal state of transitionary plasticity and mutual adjustment. After the stress and in accordance with observations about the bird nest under laboratory induced pressure, the new state can stabilize and become sticky and slower to revert to its previous state while still harboring some imprint of its previous form. 


\subsection{Dimension 4: Boundary Elements as Mechanisms of Coherence}

Internal stress effects and boundary elements are common to both bird nests and policy assemblages. Nests can be physically manipulated and stressed without losing their structural coherence. According to Weiner et al. (2020), a bird nest's jammed state holds together independent of external mechanisms: "One plausible explanation involves the additional role of flexibility in the construction process. If sticks are forced to bend while packing, some of this bending stress could be stored in the system, held by frictional contacts" (p. 8). The authors compare the intangible boundary elements resulting from internal tension and cohesion in a nest with the tangible boundary elements of an imposed structuring mechanism such as the walls of a grain silo. In the former, sticks hold their collective form without an encasement; in the latter, a pile of grain would disintegrate and sprawl outward without containment walls.

For policy assemblages, such boundary coherence can develop over time even without the imposition of meta-strategic order, as instruments mutually adjust and settle (e.g., through complementarities, concurrent resourcing, interdependencies, and value to an organizational or bureaucratic culture focused on survival through stability). This process is facilitated through repeated iterative policy cycling (Daugbjerg, 2009; Howlett, 2009), while external forces like political pressure and global crises struggle to break the institutional rigidity and coherence (Howlett \& Rayner, 2007); even outlier events like Covid-19 have proven incapable of making a more substantive policy imprint in some cases (Capano et al., 2020). Indeed, structural dissonance within an assemblage is often, paradoxically, a source of durability as the process of mutual adjustment and pruning is continuous; assemblages, like nests, often bend but do not break.

Finally, rhetorical patching and frame-building can be deployed to safeguard the political legitimacy of policies and policy assemblages by providing rationalizations of existing policy outcomes. This action is what the bird nest metaphor analogizes as the application of 'mud,' providing narrative cohesion in the absence of ex ante logical order and design. Technical and rhetorical exercises in non-design settings are often applied less to analysis of policy assemblages than to incremental and ex post adjustments for resolving problems that arise from inadequate conceptualization and absence of cohesion (Howlett \& Rayner, 2013; Wellstead et al., 2016). Various types of layering, patching, and bricolage are used to fill gaps and correct deficiencies for which no anticipatory provisions may have been conceived. As such, efforts to technically or rhetorically harmonize elements of an originally non-designed assemblage function as 'structuring mechanisms' that resemble boundary elements.

\section{Discussion and Conclusion}

Analyzing the apparent paradox of long-lasting and durable policy assemblages lacking any immediately recognizable logic or coherence eludes the application of formal structural metaphors. This conceptual puzzle invites creative new heuristics and cognitive devices that embrace nuance, fluidity, and even contradiction in moving beyond the description of such assemblages as simply 'non-designs.' There is scant analytical purchase in metaphorizing non-design only as a hopeless and random mess or failed architectural endeavor. The intentionality guiding a design process for many existing policy assemblages is quixotic; political contestation, managerialist accretion, and policy layering often yield policy patchworks that elude purely 'rational' analysis (Feindt \& Flynn, 2009; Wellstead et al., 2016). The evolutionary character of many policy assemblages in politically contested settings embodies contradictions, inconsistencies, and inefficiencies. As such, applicable descriptors or metaphors must also offer corresponding analytical depth, and the naturalistic metaphor of the bird nest is one such option. Decision-makers must work with the materials at-hand in crafting policies, and often incoherent or less rational political factors and ideologies constitute the adhesive agent ('mud') that binds together policy elements ('twigs' and 'sticks'). Although apparently rudimentary and lacking aesthetic quality, the resulting policy assemblage can be unexpectedly durable.

Rapid and haphazard policy responses to systemic crises exemplify the type of non-designed assemblages for which the bird nest metaphor provides analytical insights. For example, Covid-19 policy responses emerged from a patchwork of public health interventions, with gaps in logic and knowledge apparent and evolving over time-from the initial panic-demand for personal protective equipment and hospital ventilators to mixed messaging about mask-wearing, lock-downs, contact-tracing, and vaccine roll-outs (Capano et al, 2020). The bird nest metaphor provides the basis for a potentially richer description of how policy assemblages developed in a case like Covid-19 than do more rational descriptions based on classical notions of rational and evidence-based policymaking.

The bird nest metaphor illustrates how systems appearing to defy the directives of rationality may actually hide their own inherent order and achieve desired outcomes, even through different logics than those of formal design (Dobuzinskis, 1987). Indeed, instrumentalrationalist ways of conceiving policy assemblages have a limited field of epistemic vision that can impede the analysis of policymaking in complex settings experiencing unanticipated stresses and threats (Hartley et al., 2019). This limitation has implications not only for policy design (or the lack of it) at the 'chaotic' end of the design spectrum, but also in settings where formal intent and strategy exist but must negotiate high levels of uncertainty and complexity (Walker et al., 2013). 
In a more reflective sense, as EGT suggests, disorder need not be considered an insult to reason but can be an unrecognized driver of durability that falls outside the gaze of technocratic instrumentalism and determinism. According to Weiner et al. (2020, p. 9), "architects and artists have recently demonstrated the elegance and practical versatility that comes with embracing disorder and self-assembly instead of prescriptive control to build reconfigurable structures of emergent stability." Policymaking amidst chaos and uncertainty, for example, should embrace rather than eschew disorder as a pathway for learning, adaptation, resilience, and the avoidance of policy myopia (Nair \& Howlett, 2017b). According to Van Assche et al. (2020, p. 703), "tracing reality effects of strategy is pushing [analytical] observation to cross the boundary of inside and outside, of governance and its social-ecological environment." Even where traces of design formalism endure, the external social-ecological context often limits the predictability and deterministic function of strategic intent; conversely, an inherent institutional order can give apparent formal effect to policy assemblages that congeal in otherwise haphazard or non-designed ways.

Pursuant to this point, the practical insight of viewing policy assemblages as a bird nest is that the metaphor helps emphasize how both internal and external forces act upon policy design formation and endurance. This dynamic and the often non-designed response to policy problems are not fully articulated in, for example, Lindblom's metaphor ('muddling through') but strongly implied by EGT and theoretical work inspired by it. An example is Simon's (1969) notion of 'artificial' empirical phenomena, which are characterized by their adaptation to environmental settings and their mediation of inner and outer factors (obscuring endogenous complexity while reflecting exogenous complexity).

With reference to a bird nest, internal complexity exhibits little of what formalism or instrumental rationalism would recognize as logical, but its outward manifestation reflects imperatives visited upon it by external forces and shocks (with effectiveness exhibited by its structural resilience). In a type of evolutionary pruning, elements of the nest-as in a policy assemblage-absorb external shocks and adapt by endogenously reordering themselves and their relationships. In a policy setting, this may occur through the active re-commissioning of policy initiatives or systems that had been abandoned as a dominant pathway unfolded, or through a passive phenomenon in which elements of an assemblage are so deeply institutionalized via their interdependencies that they are under little threat of alteration or elimination by external forces.

In examining the practical usefulness of the bird nest metaphor, of particular note is how it highlights the potential resilience of non-designed policy assemblages-which need not be seen always as unfortunate accidents in need of repair but occasionally as unvarnished expressions of collective intent or situa- tional imperatives interpreted through prevailing institutional settings (and gaps or inconsistencies therein). As such, better understandings about how non-designed policy assemblages materialize, operate, and endure is a useful analytical insight for policy practitioners operating within a constellation of overlapping and often contradictory institutional settings (Turnbull, 2018). Formality in intent and design may appear to be a requisite for the endurance of policy assemblages, but this endurance can be the product also of policy components that ossify from path dependence and mutually settle into equilibrium through a process lacking design (Djanibekov \& Valentinov, 2015; Hayoz, 2015; Van Assche et al., 2014).

In closing, translating an appreciation of the informality inherent in an evolutionary system into policy practice, however uncomfortable and challenging it may be for practitioners, can be undertaken in several ways. Straightforward and immediately actionable efforts, for example, are promoted by studies urging policymakers not to 'over-design' or 'over-prescribe' policies and assemblages (empirical examples of the role of informality in the survival of institutions can be found in Boin et al., 2020). A longer-term perspective would involve the refashioning of policy design's legacy instrumental-rationalist mindset to better accommodate notions of uncertainty, precarity, precaution, and epistemic contestation (Hoppe, 2017). The latter is a fraught and complicated undertaking because it is more political than technocratic, requiring a radical interrogation of the relationship between policy and society and calling into question not only what the policy field already knows but how the field knows it and how it generates new knowledge. Given that such a reckoning has the potential to destabilize the epistemic hegemony of rationalism and the many policy structures and processes built on it, the prospects of an evolutionary enlightenment remain uncertain but warrant further scholarly and practical contemplation.

\section{Conflict of Interests}

The authors declare no conflict of interests.

\section{References}

Adam, C., Hurka, S., Knill, C., \& Steinebach, Y. (2019). Policy accumulation and the democratic responsiveness trap. Cambridge University Press.

Benyus, J. M. (1997). Biomimicry: Innovation inspired by nature. Harper Perennial.

Bemelmans-Videc, M. L. (1997). Introduction: Policy instrument choice and evaluation. In M. L. Bemelmans-Videc, R. C. Rist, \& E. Vedung (Eds.), Carrots, sticks and sermons: Policy instruments and their evaluation (pp. 21-58). Transaction Publishers.

Boin, A., Fahy, L. A., \& t Hart, P. (2020). Guardians of public value: How public organisations become and remain institutions. Springer Nature. 
Bressers, H., \& Klok, P. J. (1988). Fundamentals for a theory of policy instruments. International Journal of Social Economics, 15(3/4), 22-41.

Bubak, O. (2021). The structure-in-evolution approach: A unified view of evolutionary change in policy systems. Policy Studies. https://doi.org/10.1080/ 01442872.2021 .1908534

Capano, G., \& Howlett, M. (2020). The knowns and unknowns of policy instrument analysis: Policy tools and the current research agenda on policy mixes. SAGE Open, 10(1). https://doi.org/10.1177/ 2158244019900568

Capano, G., Howlett, M., Jarvis, D. S., Ramesh, M., \& Goyal, N. (2020). Mobilizing policy (in) capacity to fight Covid-19: Understanding variations in state responses. Policy and Society, 39(3), 285-308.

Capano, G., \& Lippi, A. (2017). How policy instruments are chosen: Patterns of decision makers' choices. Policy Sciences, 50(2), 269-293.

Capano, G., \& Woo, J. J. (2018). Resilience and robustness in policy design: A critical appraisal. Policy Sciences, 37(4), 422-440.

Cohen, M. D., March, J. G., \& Olsen, J. P. (1972). A garbage can model of organizational choice. Administrative Science Quarterly, 17(1), 1-25.

Colebatch, H. K. (2018). The idea of policy design: Intention, process, outcome, meaning and validity. Public Policy and Administration, 33(4), 365-383.

Czarniavswka, B. (2009). Emerging institutions: Pyramids or anthills? Organization Studies, 30(4), 423-441.

Daugbjerg, C. (2009). Sequencing in public policy: The evolution of the CAP over a decade. Journal of European Public Policy, 16(3), 395-411.

Daugbjerg, C. (2012). Process sequencing. In E. Araral, S. Fritzen, M. Howlett, M. Ramesh, \& X. Wu (Eds.), Routledge handbook of public policy (pp. 473-479). Routledge.

Djanibekov, N., \& Valentinov, V. (2015). Evolutionary governance, sustainability, and systems theory: The case of Central Asia. In K. Van Assche, R. Beunen, \& M. Duineveld (Eds.), Evolutionary governance theory (pp. 119-134). Springer.

Dobuzinskis, L. (1987). The self-organizing polity: An epistemological analysis of political life. Westview.

Dyckman, C. S. (2018). Planning without the planners: South Carolina's Section 319 local watershed planning process. Environmental Science \& Policy, 89, 126-141.

Enkler, J., Schmidt, S., Eckhard, S., Knill, C., \& Grohs, S. (2017). Administrative styles in the OECD: Bureaucratic policy-making beyond formal rules. International Journal of Public Administration, 40(8), 637-648.

Feindt, P. H., \& Flynn, A. (2009). Policy stretching and institutional layering: British food policy between security, safety, quality, health and climate change. British Politics, 4(3), 386-414.

Feldman, D. (2019). Chaos and dynamical systems.
Princeton University Press.

Fischer, F. (2019). Politics, values, and public policy: The problem of methodology. Routledge.

Hartley, K., \& Kuecker, G. (2021). The epistemics of public policy in an age of disruption. Cambridge University Press.

Hartley, K., Kuecker, G., \& Woo, J. J. (2019). Practicing public policy in an age of disruption. Policy Design and Practice, 2(2), 163-181.

Haydu, J. (1998). Making use of the past: Time periods as cases to compare and as sequences of problem solving. American Journal of Sociology, 104(2), 339-371.

Haydu, J. (2010). Reversals of fortune: path dependency, problem solving, and temporal cases. Theory and Society, 39(1), Article 25.

Hayoz, N. (2015). Cultures of informality and networks of power in post-Soviet non-democracies. In K. Van Assche, R. Beunen, \& M. Duineveld (Eds.), Evolutionary governance theory (pp. 73-85). Cham.

Head, B. W. (2010). Reconsidering evidence-based policy: Key issues and challenges. Policy and Society, 29(2), 77-94.

Head, B. W. (2019). Forty years of wicked problems literature: Forging closer links to policy studies. Policy and Society, 38(2), 180-197.

Hoppe, R. (2017). Heuristics for practitioners of policy design: Rules-of-thumb for structuring unstructured problems. Public Policy and Administration, 33(4), 384-408.

Howlett, M. (2009). Process sequencing policy dynamics: Beyond homeostasis and path dependency. Journal of Public Policy, 29(3), 241-262. https://doi.org/ 10.1017/S0143814X09990158

Howlett, M. (2019). The temporal dimension(s) of policy designs: Resilience, robustness and the sequencing of tools in policy mixes. International Review of Public Policy, 1(1), 27-45.

Howlett, M. (2020). Dealing with the dark side of policymaking: Managing behavioural risk and volatility in policy designs. Journal of Comparative Policy Analysis: Research and Practice, 22(6), 612-625.

Howlett, M., \& Mukherjee, I. (2014). Policy design and non-design: Towards a spectrum of policy formulation types. Lee Kuan Yew School of Public Policy.

Howlett, M., \& Mukherjee, I. (2017). Policy design: From tools to patches. Canadian Public Administration, 60(1), Article 140.

Howlett, M., Ramesh, M., \& Perl, A. (2009). Studying public policy: Policy cycles and policy subsystems (Vol. 3). Oxford University Press.

Howlett, M., \& Rayner, J. (2007). Design principles for policy mixes: Cohesion and coherence in 'new governance arrangements.' Policy and Society, 26(4), 1-18.

Howlett, M., \& Rayner, J. (2013). Patching vs packaging in policy formulation: Assessing policy portfolio design. Politics and Governance, 1(2), 170-182.

Howlett, M., \& Tosun, J. (Eds.). (2018). Policy styles and policy-making: Exploring the linkages. Routledge. 
Johnson, C. (2012). Bricoleur and bricolage: From metaphor to universal concept. Paragraph, 35(3), 355-372.

Kiel, L. D., \& Elliott, E. W. (1996). Chaos theory in the social sciences: Foundations and applications. University of Michigan Press.

Levi-Strauss, C. (1966). The savage mind. The University of Chicago Press.

Lindblom, C. E. (1959). The science of" muddling through." Public Administration Review, 19(2), 79-88.

Linder, S., \& Peters, B. G. (1991). The logic of public policy design: Linking policy actors and plausible instruments. Knowledge and Policy, 4(1/2), 125-151.

Liu, S., Yang, L., Zhang, C., Xiang, Y. T., Liu, Z., Hu, S., \& Zhang, B. (2020). Online mental health services in China during the Covid-19 outbreak. The Lancet Psychiatry, 7(4), 17-18.

Maor, M. (2020). Policy over-and under-design: an information quality perspective. Policy Sciences, 53, 395-411.

Nair, S., \& Howlett, M. (2017a). The central conundrums of policy formulation: III-structured problems and uncertainty. In M. Howlett \& I. Mukherjee (Eds.), Handbook of policy formulation (pp. 23-38). Edward Elgar.

Nair, S., \& Howlett, M. (2017b). Policy myopia as a source of policy failure: Adaptation and policy learning under deep uncertainty. Policy \& Politics, 45(1), 103-118.

Peters, B. G. (2002). Politics of bureaucracy. Routledge.

Peters, B. G., \& Tarpey, M. (2019). Are wicked problems really so wicked? Perceptions of policy problems. Policy and Society, 38(2), 218-236.

Roe, E. (2016). Policy messes and their management. Policy Sciences, 49(4), 351-372.

Simon, H. A. (1969). The sciences of the artificial. MIT Press.

Turnbull, N. (2018). Policy design: Its enduring appeal in a complex world and how to think it differently. Public Policy and Administration, 33(4), 357-364.

Van Assche, K., Beunen, R., \& Duineveld, M. (2014). Evolutionary governance theory: An introduction. Springer Science \& Business Media.

Van Assche, K., Beunen, R., \& Duineveld, M. (2017). Co-evolutionary planning theory. In M. Gunder, A. Mandanipour, \& V. Watson (Eds.), The Routledge handbook of planning theory (pp. 221-243). Routledge.

Van Assche, K., Beunen, R., Gruezmacher, M., \& Duineveld, M. (2020). Rethinking strategy in environmental governance. Journal of Environmental Policy \& Planning, 22(5), 695-708.

Walker, W. E., Marchau, V. A. W. J., \& Kwakkel, J. H. (2013). Uncertainty in the framework of policy analysis. In W. A. H. Thissen \& W. E. Walker (Eds.), Public policy analysis: New developments (pp. 215-260). Springer.

Weiner, N., Bhosale, Y., Gazzola, M., \& King, H. (2020). Mechanics of randomly packed filaments: The "bird nest" as meta-material. Journal of Applied Physics, 127(5), Article 050902.

Weirich, P. (2004). Realistic decision theory: Rules for nonideal agents in nonideal circumstances. Oxford University Press.

Weiss, C. H. (1980). Knowledge creep and decision accretion. Knowledge, 1(3), 381-404.

Wellstead, A., Rayner, J., \& Howlett, M. (2016). Alberta's oil sands reclamation policy trajectory: The role of tense layering, policy stretching, and policy patching in long-term policy dynamics. Journal of Environmental Planning and Management, 59(10), 1873-1890.

Young, T. R. (1991). Chaos and social change: Metaphysics of the postmodern. The Social Science Journal, 28(3), 289-305.

Zittoun, P. (2009). Understanding policy change as a discursive problem. Journal of Comparative Policy Analysis, 11(1), 65-82.

\section{About the Authors}

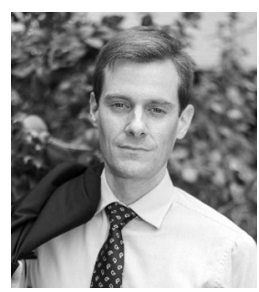

Kris Hartley is an Assistant Professor at the Department of Asian and Policy Studies, Education University of Hong Kong. He researches power and knowledge in the policymaking process, with a focus on technology and environment. Kris is also a Nonresident Fellow at the Chicago Council on Global Affairs, Visiting Fellow at the Connected Cities Lab at University of Melbourne, and Affiliated Scholar at the Center for Government Competitiveness at Seoul National University. In 2020, Kris was a Fulbright U.S. Scholar in Thailand. He has authored books published by Cambridge University Press and Routledge Press, and journal articles published in Policy Sciences, Policy and Society, Resources, Conservation \& Recycling, and others.

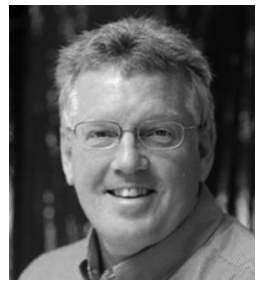

Michael Howlett is Burnaby Mountain Professor and Canada Research Chair (Tier 1) in the Department of Political Science at Simon Fraser University in Canada. He has published leading textbooks and articles on topics related to Canadian politics, natural resource and environmental policy, Canadian public policy, public policymaking and policy instruments and design, among others. His current work deals with aspects of policy formulation and policy design, including the study of policy tools and instruments and formulation processes more generally. 